\title{
Model Selection and Genetic Parameter Estimation for Performance Traits, Body Measurement Traits and Leg Score Traits in a Closed Population of Duroc Pigs
}

\author{
Kazuo FUKAWA, Toshie SUGIYAMA ${ }^{1}$, Seiji KUSUHARA ${ }^{1}$, \\ Osamu KUDOH and Kenji KAMEYAMA \\ Central Research Institute for Feed and Livestock, ZEN-NOH, Tsukuba-shi 300-4204, Japan \\ ' Faculty of Agriculture, Niigata University, Niigata-shi 950-2181, Japan
}

(Received August 3, 2000 ; Accepted January 9, 2001)

\begin{abstract}
During the course of developing a strain of Duroc pigs, 1,381 pigs were used to determine the growth rate from birth to the day at $30 \mathrm{~kg}$, the growth rate during the period from 30 to $90 \mathrm{~kg}$ of body weight, the back fat depth, the eye muscle area and leg scores when the body weight was approximately $90 \mathrm{~kg}$. Additionally, body size was measured at $90 \mathrm{~kg}$ body weight. The pigs were allowed free access to the diet. The contemporary group and gender as the fixed effects, the sire and dam as the random effects and end test weight as a covariate were taken into the mathematical model for the analysis of the data. Genetic parameters were estimated by the animal model restricted maximum likelihood (REML) method. The effect of contemporary group categorized on the basis of the test date was significant for all of the traits measured on the test starting date and thereafter. The mathematical model which contains the contemporary group of one-week period tended to show a better Akaike's Information Criterion (AIC) than groups of two and four-week period. Significant differences between genders (boar, gilt, barrow) were observed in most of the traits. The effect of end test weight as a covariate was significant in all of the traits measured at approximatcly $90 \mathrm{~kg}$ body weight. Estimates of the heritability of performance traits and body measurement traits generally varied from moderate to high. The heritability of leg score traits was low. Although an unfavorable genetic correlation between back fat depth and leg score traits was observed, the genetic correlation between leg score traits and daily gain during the period from 30 to $90 \mathrm{~kg}$ of body weight was favorable. The results suggest that the simultaneous improvement of the growth rate and leg score traits is not difficult in Duroc pigs, but there might be difficulty in the improvement of obtaining less back fat depth and better leg soundness.
\end{abstract}

Animal Science Journal 72 (2):97-106, 2001

Key words : Duroc, Leg score, Growth rate, REML, Heritability

In Japan, pig improvement programs have been implemented using relatively small closed nucleus populations (i.e. 10 boars, 50 sows) in a number of national and prefectural experimental stations. In these projects, the generations usually do not overlap, and boars and sows are replaced within one year. Selection is usually continued for 6 to 7 generations for the purpose of exceeding a specific performance level in terms of the selection objectives. The size of the population is relatively small and all gilts in the same generation usually farrow within the same twoor three-month period. Because all growing pigs are born in a relatively brief period, pigs born in one generation are assumed to be in the same

Corresponding : Kazuo FUKAWA (fax : +81 (0) 298-69-1071, e-mail : fukawa@zk.zennoh.or.jp)

Anim. Sci. J. 72 (2) : 97-106, 2001 
contemporary groups.

Usually, data on the performance of individual pigs are directly used as variates of selection indices without correction. Recently, the multiple trait individual animal model BLUP method proposed by Henderson ${ }^{7}$ has been adopted in pig breeding in various nations ${ }^{(4)}$ including Japan ${ }^{11)}$. The superiority of the BLUP method has been suggested by many researchers ${ }^{19.21 .25}$. BLUP can be an effective method for correction of environmental effects even in a situation where the total testing period for selected groups is relatively brief and the pigs are reared within one herd.

For estimation of breeding value, one can use a BLUP package such as PEST $^{4)}$ or MBLUP ${ }^{18)}$ more easily than pedigree indices because it may be necessary to use different indices for animals belonging to different families. Using these packages, multivariate selection for better performance, better body conformation and better leg soundness is possible, provided that the correct genetic parameter is available.

Before adopting the BLUP method, selection of an appropriate model for fixed and random effects is necessary. The types of mathematical models applied affect the outcome of genetic parameter estimation also.

In this study, the effectiveness of models in estimating genetic parameters and breeding value in terms of performance traits, body measurement traits and leg score traits was investigated. After investigation of the models, the genetic parameters essential for multiple trait selection in terms of performance traits, body conformation traits and leg traits were estimated.

\section{Materials and Methods}

\section{Testing and selection methods}

Data were obtained from a closed population of Duroc pigs. The data set consists of performance data for 1,381 pigs tested during the period from 1991 to 1997 (generations 1 to 6) in three different herds. In each generation, boars were eliminated from the population after finishing service to gilts or sows in the same generation. Sows were eliminated from the populations after weaning primiparous or second parity litters. Accordingly, the generations did not

Anim. Sci. J. 72 (2) : 97-106, 2001 overlap. In each generation, all sows farrowed within the same three-month period. In generation 5 , sows farrowed the second parity piglets within three-month period also.

Pigs were born and tested in a breeding farm in Kumamoto prefecture from 1991 to 1993 (generations 1 and 2), one in Ibaraki prefecture from 1993 to 1996 (generations 3 to 6 ) and one in Iwate prefecture in 1997 (generation 6). In generation 6, the first parity piglets of generation 5 sows were tested in Ibaraki prefecture. Additionally, the second parity piglets were introduced into the farm in Iwate prefecture by Caesarian section and tested.

On the day of birth, weights of 1,317 piglets were measured. The growth rate during the period when the body weight increased from approximately 30 to $90 \mathrm{~kg}$ was measured. At approximately $90 \mathrm{~kg}$ body weight, the back fat depth and the eye muscle area at the mid point between the front end center of ear roots and the root of the tail were measured ultrasonically by means of Kaijyo Corporation. USL-12, SR-100 and Aloka Co. Ltd. SSD-500 instruments. USL-12 instrument was used in generation 1 and 2, while SR-100 or SSD-500 was used in the subsequent generations. Also, the body length, withers height, chest girth and cannon circumference of each pig were measured at this time. In addition, At approximately $90 \mathrm{~kg}$ body weight, the leg weakness of each pig was scored in terms of cannon circumference, claw, front leg, rear leg and gait scores ${ }^{8}$.

Pigs in generations 1 and 2 were fed a diet with $12 \%$ digestive crude protein (DCP) and $74.5 \%$ total digestive energy (TDN). In the case of the pigs in generations 3 to 6 , growing pigs were fed a diet with $16 \%$ DCP and $78 \%$ TDN during the period when the body weight increased from 30 to $60 \mathrm{~kg}$, and finishing pigs were fed a diet with 12\% DCP and 68\% TDN during the period when the body weight increased from 60 to $90 \mathrm{~kg}$. Pigs were reared in groups of 3 to 11 pigs, with free access to water and the diet.

\section{Statistical methods}

Three contemporary groups (CTP) separated with three different intervals $(1,2$ and 4 weeks, respectively), were interactively included in models to investigate the effect in the analysis of 15 performance 
traits : daily gain from birth to $30 \mathrm{~kg}$ (DG1), daily gain from 30 to $90 \mathrm{~kg}$ (DG2), back fat depth (BFD), eye muscle area $(\mathrm{EM})$, body length $(\mathrm{BL})$, withers height (WH), chest girth ( $\mathrm{CHG}$ ), cannon circumference (CC), cannon circumference score (CCS), claw score (CS), front leg score (FLS), rear leg score (RLS), gait score (GS), sum of leg scores (SLS) and aggregate leg score (ALS). The effect of the gender of the pigs was included in the models as a fixed effect, and the sire and dam of each tested pig were included in the models as random effects. Additionally, end test weight (ETW) was included in the models as a covariate.

The $\mathrm{AIC}^{1 /}$ for each model with different contemporary group periods (model 1 with a one-week period, model 2 with a two-week period and model 3 with a four-week period) was obtained by the MIXED procedure of SAS ${ }^{17)}$ using restricted maximum likelihood (REML) method ${ }^{16)}$ and these values were compared to investigate the effect of altering the time interval to separate the CTP. The equation for estimating AIC was as follows :

\section{$\mathrm{AIC}=\mathrm{Log} \mathrm{L}-\mathrm{K}$}

where $\log L$ is REML $\log$ likelihood and $K$ is the numbers of covariance parameters.

After selecting the CTP period which brought us the best AIC, the least square means of the fixed effects and the variance components of random effects were estimated by the same procedure. The mathematical model used for the analysis was as follows :

$$
\mathrm{Y}_{\mathrm{ijk}}=\mu+\mathbf{C T P}_{\mathrm{r}}+\mathrm{SE}_{\mathrm{s}}+\beta \mathrm{X}_{\mathrm{ijk}}+\mathrm{S}_{\mathrm{i}}+\mathbf{D}_{\mathrm{j}}+\varepsilon_{\mathrm{ijk}}
$$

where $Y_{\mathrm{ijk}}$ is the observed data, $\mu$ is the overall mean, $C T P_{\mathrm{r}}$ is the fixed effect of the rth CTP (from 1 to 92,50 , and 30 in model 1, 2 and 3 respectively), $\mathrm{SE}_{\mathrm{s}}$ is the fixed effect of the sth gender ( 1 to 3 ; boar, gilt, barrow), $\beta$ is the regression coefficient of the covariate ETW for each trait, $X_{\mathrm{ijk}}$ is the ${ }_{\mathrm{j} j \mathrm{k}}$ th observed data of covariate, $S_{i}$ is the random effect of the ith Sire, $D_{j}$ is the random effect of the $j$ th Dam and $\varepsilon_{i j k}$ is the random effect of residual error.

Using the same fixed effect and covariate, genetic parameters were estimated using VCE3.2 $2^{\text {s) }}$.

The model used for the estimation was as follows :

Anim. Sci. J. 72 (2) : 97-106, 2001

$$
\mathbf{Y}_{\mathrm{i}}=\mu+\mathbf{C T P}_{\mathrm{r}}+\mathbf{S E}_{\mathrm{s}}+\beta \mathbf{X}_{\mathrm{i}}+\mathbf{A}_{\mathrm{i}}+\varepsilon_{\mathrm{i}}
$$

where $Y_{i}$ is the observed data of the trait, $\mu$ is the overall mean, CTP $_{r}$ is the fixed effect of the rth CTP (from 1 to 92), $\mathrm{SE}_{\mathrm{s}}$ is the fixed effect of the sth gender, $\beta$ is the regression coefficient of the covariate ETW, $X_{i}$ is the observed data of the covariate ETW, $A_{i}$ is the random effect of the ith animal and $\varepsilon_{\mathrm{i}}$ is the random effect of residual error.

For estimation of genetic correlation, the model was expanded to a multivariate linear mixed model.

\section{Result}

\section{Description of the data}

The basic statistics of the traits are shown in Table 1.

For performance traits and body measurement traits, the coefficients of skewness were generally positive but small and continuously distributed. However, since score traits were discretely distributed and the classes of scores were within the range of 3 to 10 , the coefficients of skewness were negative and the deviation from zero were relatively large.

Comparison of the models with the different contemporary groups

The AIC values obtained for the three different CTP are shown in Table 2. The model with the largest AIC value tends to be the preferable model ${ }^{17)}$. Most of the traits in model 1 where the CTP was set as a one-week period, had the largest AIC value, except for BFD, CCS and FLS. The BFD and CCS in model 3 where CTP was set as a four-week period, had the largest AIC value. The FLS in model 2 where CTP was set as a two-week period, had the largest AIC value.

\section{Estimation of fixed and random effects}

Restricted maximum likelihood estimations of fixed effects of gender, the significance level of CTP, the significance level of covariate ETW and the variance component of sire and dam are shown in Table 3. Model 1 having a one-week period CTP, was used for the estimation. The effect of CTP was significant for all traits, when CTP was included in the model. The birth weight in CTP was not included in the model, since the inclusion of CTP grouped according to test date (about 70 days after birth) makes no sense. A 
FUKAWA, SUGIYAMA, KUSUHARA, KUDOH and KAMEYAMA

Table 1. Description of the data

\begin{tabular}{|c|c|c|c|c|c|c|}
\hline Trait & $\begin{array}{l}\text { No. of } \\
\text { records }\end{array}$ & Mean & $\begin{array}{l}\text { Standard } \\
\text { deviation }\end{array}$ & Min. & Max. & $\begin{array}{l}\text { Coefficient of } \\
\text { Skewness }\end{array}$ \\
\hline \multicolumn{7}{|c|}{ Performance and body measurement traits } \\
\hline Birth weight (BW) & 1,317 & 1. 38 & 0.25 & 0.64 & 2.30 & 0.14 \\
\hline End test weight $(\mathrm{ETW})^{\mathrm{a}}$ & 1,381 & 91.88 & 2. 40 & 82.00 & 108.00 & 1.86 \\
\hline $\begin{array}{l}\text { Daily gain from birth to } 30 \mathrm{~kg} \\
\text { (DG1) }\end{array}$ & 1,381 & 440.10 & 51.10 & 300.00 & 618.90 & 0.12 \\
\hline $\begin{array}{l}\text { Daily gain from } 30 \mathrm{~kg} \text { to } 90 \mathrm{~kg} \\
\text { (DG2) }\end{array}$ & 1,379 & 826.20 & 86.02 & 550.50 & $1,171.70$ & 0.04 \\
\hline $\begin{array}{l}\text { Back fat depth at mid loin } \\
\text { (BFD) }\end{array}$ & 1,377 & 2. 72 & 0.04 & 0.89 & 3.28 & 0.92 \\
\hline Eye muscle area $(\mathrm{EM})$ & 1,379 & 35.89 & 0.39 & 23.60 & 50.70 & 0.12 \\
\hline Body length (BL) & 1,380 & 104. 10 & 3.56 & 93.00 & 117.00 & 0.38 \\
\hline Withers height (WH) & 1,380 & 61.24 & 2.80 & 51.40 & 72.40 & 0.52 \\
\hline Chest girth (CHG) & 1,378 & 102.20 & 3.21 & 87.00 & 115.00 & 0.53 \\
\hline Cannon circumference $(\mathrm{CC})$ & 1,381 & 17.55 & 0.78 & 14.50 & 20.80 & 0.25 \\
\hline \multicolumn{7}{|l|}{ Leg score traits ${ }^{b}$} \\
\hline $\begin{array}{l}\text { Cannon circumference score } \\
\text { (CCS) }\end{array}$ & 1,158 & -0.17 & 0.38 & -2 & 0 & -1.95 \\
\hline Claw score (CS) & 1,158 & -0.50 & 0.63 & -2 & 0 & -0.90 \\
\hline Front leg score (FLS) & 1,158 & -0.26 & 0.53 & -2 & 0 & -1.95 \\
\hline Rear leg score (RLS) & 1,158 & -0.61 & 0.67 & -2 & 0 & -0.65 \\
\hline Gait score (GS) & 1,158 & -0.41 & 0.61 & -2 & 0 & -1.14 \\
\hline Sum of leg scores (SLS) & 1,158 & -1.95 & 1.85 & -10 & 0 & -0.82 \\
\hline Aggregate leg scorec ${ }^{c}$ & 1,158 & 3.99 & 1.08 & 1 & 5 & -0.58 \\
\hline
\end{tabular}

${ }^{a}$ Abbreviations are shown in parentheses.

${ }^{b}$ Leg scores were from 0 (good) to -2 (bad).

${ }^{c}$ Aggregate leg scores were determined according to the sum of leg scores:

$0,-1$ : Very sound (5)

-2 : Sound (4)

$-3,-4:$ Intermediate (3)

-5 to -7 : Weak (2)

-8 to $-10:$ Very weak (1)

significant difference between genders was found in most of the traits except for FLS. Boars had heavier weight than gilts. The DG1 of boars was the largest $(431.01 \mathrm{~g})$, whereas barrows was the smallest (408.28 g). The DG2 of barrows was the best $(890.2 \mathrm{~g})$, whereas gilts was the worst $(827.1 \mathrm{~g})$. The BFD of boars was the leanest $(1.566 \mathrm{~cm})$, whereas barrows was the deepest $(1.989 \mathrm{~cm})$. Gilts had bigger eye muscle area $\left(36.23 \mathrm{~cm}^{2}\right)$ than boars or barrows $(34.65$ $\mathrm{cm}^{2}$ and $34.65 \mathrm{~cm}^{2}$, respectively).

Barrows had shorter body length $(102.66 \mathrm{~cm})$ than boars or gilts $(104.17 \mathrm{~cm}$ and $104.05 \mathrm{~cm}$, respectively). Withers height was greater in boars $(62.07 \mathrm{~cm})$ than in gilts $(61.19 \mathrm{~cm})$ or barrows $(60.78 \mathrm{~cm})$. Chest girth (CHG) was smaller in boars $(101.42 \mathrm{~cm})$ than in gilts or barrows $(103.07 \mathrm{~cm}$ and $103.13 \mathrm{~cm}$, respectively). 
Genetic Parameter Estimation for Performance Traits

Table 2. Comparison of Akaike's Information Criterion values obtained with three alternative models for each production and body measurement trait

\begin{tabular}{ccccccccc}
\hline \hline & \multicolumn{2}{c}{ Trait } & & & & & & \\
& DG1 & DG2 & BFD & EM & BL & WH & CHG & CC \\
\hline Model 1 $^{\mathrm{a}}$ & -6267.57 & -7441.43 & -396.85 & -3578.46 & -3322.97 & -2918.23 & -3107.92 & -1267.87 \\
Model 2 $^{\mathrm{b}}$ & -6559.08 & -7696.32 & -376.28 & -3656.87 & -3404.94 & -2981.27 & -3182.80 & -1271.47 \\
Model 3 $^{\mathrm{c}}$ & -6666.67 & -7666.34 & -360.75 & -3704.52 & -3449.35 & -3014.53 & -3208.57 & -1286.40 \\
\hline
\end{tabular}

\begin{tabular}{|c|c|c|c|c|c|c|c|}
\hline & Trait & & & & & & \\
\hline & $\mathrm{CCS}$ & $\mathrm{CS}$ & FLS & RLS & GS & SLS & ALS \\
\hline Model 1 & -476.56 & -1074.66 & -887.24 & -1120.79 & -1038.67 & -2203.11 & -1632.12 \\
\hline Model 2 & -457.04 & -1079.09 & -883.85 & -1135.17 & -1041.23 & -2244.45 & -1657.06 \\
\hline Model 3 & -451.94 & -1079.32 & -883.95 & -1130.47 & -1042.78 & -2262.93 & -1665.31 \\
\hline
\end{tabular}

${ }^{\mathrm{a}}$ Model 1 :

Fixed effects: Gender and contemporary group (one-week period).

Random effects : Sire and Dam.

Covariate : End test weight (DG2, BFD, EM, BL, WH, CHG and CC).

${ }^{\mathrm{b}}$ Model 2 :

Effects were the same as those in the case of Model 1 except that contemporary groups were set with a two-week period.

${ }^{c}$ Model 3 :

Effects were the same as those in the case of Model 1 except that contemporary groups were set with a four-week period.

Cannon circumference was larger in boars $(17.93 \mathrm{~cm})$ than in gilts or barrows $(17.15 \mathrm{~cm}$ and $17.32 \mathrm{~cm}$, respectively). Concerning leg weakness scores, boars had better scores than gilts or barrows in terms of CCS. Boars and gilts had higher scores than barrows in terms of CS and RLS. As for the sum of leg scores and aggregate leg scores, boars had the best scores ( -1.685 and 4.126 , respectively), whereas barrows had the worst ones ( -2.775 and 3.467 , respectively). CTP had a significant effect on all of the traits measured after the test date except on BW. For all of the traits measured when the body weight was approximately $90 \mathrm{~kg}$, end test weight (ETW) had a significant effect $(P<0.05)$ as a covariate. The estimated heritability by sire model ( 4 times the sire component variance ratio) ranged from 0.104 (CCS) to 0.636 (BW). The heritability values for leg score traits were relatively low (from 0.104 in the case of CCS to
0.230 in the case of SLS), whereas the heritability values ranged from low to high in the case of the performance and body measurement traits (from 0.191 in the case of EM to 0.636 in the case of BW).

\section{Genetic parameter estimation}

Animal model REML estimates of heritability, phenotypic correlation and genetic correlation are shown in Table 4.

The heritability values for performance trait ranged from 0.22 (EM) to 0.58 (BFD). The heritability of birth weight was high (0.43). On the other hand, the heritability of EM was low (0.22). The estimates of heritability for all the performance trait obtained by means of the animal model (Table 4) were similar to those obtained by the sire model (Table 3 ). The heritability values for body measurement traits were moderate values (from 0.27 in the case of BL to 0.32 in the case of $\mathrm{CHG}$ ). The estimates of heritability 
FUKAWA, SUGIYAMA, KUSUHARA, KUDOH and KAMEYAMA

Table 3. REML estimate of the mean for each gender, the significance of the testing period and the regression coefficient of ETW for each trait

\begin{tabular}{|c|c|c|c|c|c|c|c|c|}
\hline \multirow[b]{2}{*}{ Effect } & \multicolumn{8}{|l|}{ Trait } \\
\hline & BW & DG 1 & $\mathrm{DG} 2$ & $\mathrm{BFD}$ & $\mathrm{EM}$ & $B L$ & WH & $\mathrm{CHG}$ \\
\hline \multicolumn{9}{|l|}{ Gender } \\
\hline Boar & 1. $447 \mathrm{a}^{1)}$ & 431. 01a & $837.6 b$ & $1.566 \mathrm{c}$ & $34.65 b$ & $104.17 \mathrm{a}$ & $62.07 a$ & $101.42 \mathrm{~b}$ \\
\hline Gilt & $1.389 \mathrm{~b}$ & $426.29 b$ & 827. lc & $1.890 \mathrm{~b}$ & $36.23 a$ & $104.05 a$ & $61.19 b$ & $103.07 \mathrm{a}$ \\
\hline Barrow & 1. $386 b$ & $408.28 c$ & $890.2 a$ & $1.989 \mathbf{a}$ & $34.65 b$ & $102.66 \mathrm{~b}$ & $60.78 b$ & $103.13 a$ \\
\hline $\begin{array}{l}\text { Significance of } \\
\text { the testing period }\end{array}$ & $-5)$ & $* * * 2)$ & $* * *$ & $* * *$ & $* * *$ & $* * *$ & $* * *$ & $* * *$ \\
\hline $\begin{array}{l}\text { Significance of } \\
\text { covariate ETW }\end{array}$ & - & - & $* * *$ & $* * *$ & $* * *$ & $* * *$ & $* * *$ & $* * *$ \\
\hline \multicolumn{9}{|c|}{ Variance component } \\
\hline Sire & 0.010 & 170.11 & 520.54 & 0.013 & 0.660 & 0.667 & 0.406 & 0.617 \\
\hline Dam & 0.025 & 472.76 & 892.30 & 0.020 & 1. 689 & 0.505 & 0.268 & 0.482 \\
\hline Residual & 0.031 & 607.07 & 4541.63 & 0.075 & 11. 465 & 7.913 & 4.202 & 5.595 \\
\hline Heritability $^{4}$ & 0.636 & 0.544 & 0.350 & 0.478 & 0.191 & 0.294 & 0.333 & 0.369 \\
\hline \multicolumn{9}{|c|}{ Trait } \\
\hline Effect & $\mathrm{CC}$ & $\mathrm{CCS}$ & $\mathrm{CS}$ & FLS & RLS & GS & SLS & ALS \\
\hline \multicolumn{9}{|l|}{ Gender } \\
\hline Boar & $17.93 \mathrm{a}$ & $-0.057 \mathrm{a}$ & $-0.420 \mathrm{a}$ & -0.267 & $-0.540 \mathrm{a}$ & -0.400 & $-1.685 a$ & 4. $126 \mathrm{a}$ \\
\hline Gilt & $17.15 b$ & $-0.215 b$ & $-0.484 a$ & -0.243 & $-0.585 a$ & -0.397 & $-1.918 b$ & 3. $997 \mathrm{~b}$ \\
\hline Barrow & $17.32 \mathrm{~b}$ & $-0.341 b$ & $-0.758 b$ & -0.325 & $-0.840 b$ & -0.495 & $-2.775 c$ & 3. $467 \mathrm{c}$ \\
\hline $\begin{array}{l}\text { Significance of } \\
\text { the testing period }\end{array}$ & $* * *$ & $* * *$ & $* * 3)$ & $* * *$ & $* * *$ & $* * *$ & $* * *$ & $* *$ \\
\hline $\begin{array}{l}\text { Significance of } \\
\text { covariate ETW }\end{array}$ & $* * *$ & - & - & - & - & - & - & - \\
\hline \multicolumn{9}{|c|}{ Variance component } \\
\hline Sire & 0.011 & 0.003 & 0.013 & 0.008 & 0.014 & 0.013 & 0.179 & 0.056 \\
\hline Dam & 0.057 & 0.009 & 0.032 & 0.012 & 0.016 & 0.023 & 0.313 & 0.118 \\
\hline Residual & 0.315 & 0.110 & 0.331 & 0.241 & 0.372 & 0.313 & 2.622 & 0.909 \\
\hline Heritability & 0.118 & 0.104 & 0.142 & 0.121 & 0.141 & 0.148 & 0.230 & 0.208 \\
\hline
\end{tabular}

${ }^{1)}$ Means with a different superscript, $a, b$, and $c$, are significantly different $(\mathbf{P}<0.05)$.

2) *** : Significantly different from zero $(\mathrm{P}<0.005)$.

3)**: Significantly different from zero $(\mathrm{P}<0.01)$.

4) Heritability was estimated by sire model.

${ }^{5)}$ Not included in the model. 
for body measurement traits were similar to those obtained by means of the sire model except for $\mathrm{CC}$ ( 0.118 in sire model and 0.30 in animal model). The heritabilities of leg scores were low (from 0.06 in the case of CCS to 0.24 in the case of CS).

A highly positive correlation was observed between BFD and CHG, between CS and RLS, between FLS and GS and between RLS and GS, respectively with respect to phenotypic correlation estimates. The correlation estimates between total leg scores (SLS and ALS) and other leg scores were also very high. The correlation estimates between $\mathrm{BW}$ and growth traits (DG1 and DG2) was positive $(0.26$ and 0.18 , respectively). There was a negative correlation between BFD and DG1, whereas the correlation between BFD and DG2 was positive.

A highly positive correlation was observed between BW and DG1, whereas a slightly negative correlation was observed between $\mathrm{BW}$ and DG2 with respect to the genetic correlation estimates. The genetic correlation between BW and each of the body measurement or leg score traits was inconsistent and low. Although the correlation between DG1 and each of the leg score traits was low and inconsistent, the correlation between DG2 and each of the leg score traits was moderately positive (from 0.13 in the case of RLS to 0.44 in the case of GS) except for CCS $(0.00)$. A moderate or high correlation was observed between BFD and each of the body measurement traits (from -0.38 in the case of WH to 0.61 in the case of $\mathrm{CHG}$ ). The correlation between $\mathrm{BFD}$ and each of the leg score traits was moderately or highly positive (from 0.25 in the case of CS to 0.88 in the case of GS). An antagonistic genetic correlation was observed between $\mathrm{BL}$ and each of the leg score traits. In the case of some leg score traits, the correlation could not be estimated because the likelihood did not converge. However, the genetic correlation between these traits was highly positive (from 0.66 in the case of RLS-GS to 0.98 in the case of RLS-ALS).

\section{Discussion}

\section{Description of the data}

The class of scores for leg score traits was only 3 . Therefore, the coefficients of skewness were large.
However, several researchers have reported that estimated fixed and random effects were highly correlated comparing estimates obtained by means of linear and threshold models for fertility and score type traits in dairy cattle ${ }^{23,24)}$. Moreover, the correlation between estimates obtained by means of the linear and threshold models would be higher in the case of a multinomial model than in the case of a binomial model. Thus, a linear model for leg scores was a dopted. Concerning measurement by ultrasonography (BFD and EM), the machines which were used for measuring back fat depth and eye muscle area was different among the generations. However, Kaijyo Denki USL-12 and SR-100 had basically the same mechanical system and showed very similar images. Moreover, The comparison between the values of BFD and EMA measured by SR-100 and Aloka SSD-500 indicated very high correlation. Therefore, the type of machine was not included in the mathematical model, and the measured data were directly used for the analysis.

Comparison of the models with different contemporary groups

Preliminary analysis indicated that contemporary groups categorized on the basis of the test date had a significant effect in analysis of all of the traits measured after the test date. Application of the three different contemporary groups to the REML model resulted in different AIC values. This implies that the type of contemporary group affected the fitness of the model, and finally affected the estimate of breeding value. Wada and Kashiwagi ${ }^{22}$ suggested that the AIC value is a useful indicator for choosing a better model for estimation of breeding value.

\section{Estimation of fixed and random effects}

No difference in BW of boars and barrows is expected, as barrows are intact males at the time of birth. However, the barrows were animals chosen for use as test pigs for evaluation of meat quality, and rather small pigs were selected. This may explain the observed difference in BW between boars and barrows. While barrows had the best growth rate in DG2, they had the worst growth rate in DG1. The difference might be caused by castration.

The observed differences in leg score traits were 
FUKAWA, SUGIYAMA, KUSUHARA, KUDOH and KAMEYAMA

Table 4. Genetic parameters of performance, body measurement and leg score traits

\begin{tabular}{|c|c|c|c|c|c|c|c|c|}
\hline & $\mathrm{BW}$ & DG1 & $\mathrm{DG} 2$ & BFD & EM & BL & WH & $\mathrm{CHG}$ \\
\hline BW & $0.43^{11}$ & $0.50^{23}$ & -0.11 & -0.11 & -0.11 & 0.01 & 0.33 & -0.25 \\
\hline DG1 & $0.26 * * *$ & 0.43 & 0.38 & 0.27 & 0.18 & 0.03 & 0.24 & 0.09 \\
\hline DG2 & $0.18 * * *$ & 0.08 & 0.32 & 0.40 & -0.30 & -0.38 & -0.52 & 0.45 \\
\hline BFD & $-0.13^{* * *}$ & $-0.12^{* * *}$ & $0.28 * * *$ & 0.58 & -0.19 & -0.42 & -0.38 & 0.61 \\
\hline $\mathrm{EM}$ & $-0.09^{31}$ & 0.09 & 0.04 & 0.07 & 0.22 & 0.36 & 0.36 & 0.05 \\
\hline $\mathrm{BL}$ & 0.01 & -0.09 & $-0.18^{* * *}$ & -0.01 & 0.01 & 0.27 & 0.58 & -0.44 \\
\hline WH & $0.16 * * * 4\}$ & $-0.32^{* * *}$ & $-0.15^{* * *}$ & $-0,20 * * *$ & $-0.15^{* * *}$ & $0.12 * * *$ & 0.30 & -0.15 \\
\hline $\mathrm{CHG}$ & $-0.10^{* 6)}$ & $-0.13^{* * *}$ & $0.19 * * *$ & $0.48 * * *$ & $0.15^{* * *} *$ & 0.08 & -0.03 & 0.32 \\
\hline $\mathrm{CC}$ & 0.04 & -0.01 & -0.03 & $-0.26^{* * *}$ & -0.06 & $0.15 * * *$ & $0.13 * * *$ & 0.02 \\
\hline $\mathrm{CCS}$ & 0.06 & $0.11 *$ & 0.09 & $-0.17 * * *$ & 0.09 & 0.03 & -0.02 & -0.01 \\
\hline $\mathrm{CS}$ & 0.05 & 0.03 & 0.10 & -0.02 & 0.03 & -0.05 & 0.10 & 0.01 \\
\hline FLS & -0.02 & 0.06 & 0.08 & 0.08 & $0.11^{*}$ & -0.01 & -0.05 & 0.08 \\
\hline RLS & 0.00 & -0.07 & 0.05 & 0.05 & 0.03 & $-0.11^{*}$ & 0.10 & 0.04 \\
\hline GS & -0.02 & 0.05 & 0.08 & -0.01 & 0.08 & -0.08 & -0.02 & 0.04 \\
\hline SLS & 0.02 & 0.04 & $0.12^{* * 5 !}$ & 0.00 & 0.10 & -0.08 & 0.04 & 0.05 \\
\hline \multirow[t]{2}{*}{ ALS } & 0.02 & 0.04 & $0.11 *$ & -0.01 & 0.08 & -0.07 & 0.04 & 0.04 \\
\hline & $\mathrm{CC}$ & $\mathrm{CCS}$ & $\mathrm{CS}$ & FLS & RLS & GS & SLS & ALS \\
\hline BW & 0.14 & 0.08 & -0.04 & -0.29 & -0.09 & -0.41 & -0.17 & -0.01 \\
\hline DG1 & -0.27 & -0.26 & 0.04 & 0.03 & 0.27 & -0.20 & -0.01 & -0.04 \\
\hline DG2 & -0.40 & 0.00 & 0.21 & 0.27 & 0.13 & 0.44 & 0.36 & 0.28 \\
\hline BFD & -0.52 & -0.09 & 0.25 & 0.57 & 0.48 & 0.88 & 0.43 & 0.40 \\
\hline EM & -0.14 & -0.31 & 0.28 & 0.23 & -0.07 & 0.16 & -0.09 & -0.16 \\
\hline $\mathrm{BL}$ & -0.16 & -0.42 & -0.43 & -0.44 & -0.03 & -0.63 & -0.41 & -0.32 \\
\hline WH & -0.07 & -0.40 & -0.08 & -0.06 & -0.10 & 0.00 & 0.08 & 0.17 \\
\hline $\mathrm{CHG}$ & -0.49 & -0.14 & 0.03 & 0.25 & 0.29 & 0.49 & 0.13 & 0.22 \\
\hline $\mathrm{CC}$ & 0.30 & 0.77 & 0.22 & -0.06 & -0.15 & 0.02 & 0.19 & 0.24 \\
\hline CCS & $0.34 * * *$ & 0.06 & 0.25 & 0.49 & 0.00 & 0.55 & 0.67 & 0.57 \\
\hline $\mathrm{CS}$ & 0.03 & $0.19 * * *$ & 0.24 & 0.90 & 0.92 & 0.90 & 0.97 & 1.00 \\
\hline FLS & 0.01 & $0.14^{* * *}$ & $0.21 * * *$ & 0.08 & 0.94 & $\mathrm{NE}^{7\rangle}$ & $\mathrm{NE}$ & 0.92 \\
\hline RLS & 0.01 & 0.07 & $0.42 * * *$ & $0.15 * * *$ & 0.13 & 0.66 & 0.94 & 0.98 \\
\hline GS & 0.03 & $0.15 * * *$ & $0.35 * * *$ & $0.41 * * *$ & $0.49 * * *$ & 0.09 & 0.93 & 0.83 \\
\hline SLS & 0.09 & $0.39 * * *$ & $0.71 * * *$ & $0,58 * * *$ & $0.72 * * *$ & $0.77 * * *$ & 0.15 & $\mathrm{NE}$ \\
\hline ALS & 0.09 & $0.36 * * *$ & $0.69 * * *$ & $0.54 * * *$ & $0.69 * * *$ & $0.76 * * *$ & $0.96 * * *$ & 0.19 \\
\hline
\end{tabular}

\footnotetext{
1) : Diagonal : heritability.

2) : Upper triangle: Genetic correlation.

${ }^{3)}$ : Lower triangle : Phenotypic correlation.

4. : *** $\mathrm{P}<0.005$

s) : $* * \mathrm{P}<0.01$

6) : $\quad * \mathrm{P}<0.05$

7): NE : Not estimable.
} 
inconsistent with the reports of other researchers. Jorgensen $^{9)}$ reported an inconsistency in the difference in several leg score traits between genders. Grondalen $^{6)}$ and Goedegebuure et al. ${ }^{3)}$ reported that boars had poorer leg soundness than gilts. The scoring standards were different among these reports, and the difference might be associated with this inconsistency.

\section{Genetic parameter estimation}

Although heritability estimates by animal model were generally consistent with ones by sire model, a large difference was observed in $\mathrm{CC}(0.30$ and 0.118 in animal and sire model respectively). The reason might be that the entire pedigree information was used in animal model estimation, while only the ratio of sire variance component to total variance was used in sire model. The estimated heritability of BW (0.44) in animal model was higher than that reported by Lakhani and Bhadauria ${ }^{12}(0.13)$. Since a common environmental effect $\left(c^{2}\right)$ was not included in the model as a random effect, $c^{2}$ may have been included in the heritability.

The estimated heritability of DG1 (0.43 in animal model and 0.544 in sire model) was higher than that of DG2 0.32 in animal model and 0.35 in sire model). High heritability of DG1 may also be due to a common environmental effect. The estimated heritability of DG2 and that of BFD were consistent with estimates reported by Cameron and Curran ${ }^{2)}$ and $\mathrm{Li}$ and Kennedy ${ }^{13)}$. There have been few reports about estimates of the heritability of body measurement traits. Van Steenbergen et al. ${ }^{20}$ reported that the heritability values for shoulder-loin length and width were 0.28 and 0.38 , respectively. These values are very close to our estimates for $\mathrm{BL}$ and $\mathrm{CHG}$ in Animal model ( 0.27 and 0.32 , respectively), although the method of measurement was different.

The animal model estimates of the heritability of leg score traits in this study, ranging from 0.08 to 0.24 , were generally consistent with results obtained by Lundeheim ${ }^{15)}$ and van Steenbergen et al. ${ }^{20)}$.

The positive relationship between DG2 and BFD was consistent with results obtained by other researchers ${ }^{2,13)}$ for animals given free access to the diet. The favorable positive genetic correlation be- tween average daily gain and leg score traits observed in this study was consistent with the findings of Kadowaki et al. ${ }^{10)}$, while not observed in other studies ${ }^{15,20)}$. The unfavorable genetic association between leg score traits and BFD or BL was generally consistent with results obtained by Kadowaki et al. ${ }^{10}$, Lundeheim ${ }^{15)}$ and van Steenbergen et al. ${ }^{20)}$.

In western countries where lean percentage is a primary concern in terms of breeding objectives, strong selection against back fat depth may lead to deterioration of leg soundness. On the other hand, in Japan where maintenance of adequate back fat depth is one of the important breeding objectives, improvement of leg soundness and maintenance of adequate back fat depth through appropriate selection may not be difficult. Restricted or desired selection indices may help in improving these traits. Our results and those reported by Kadowaki et al. ${ }^{10)}$ suggested that improvement of the growth rate did not affect leg soundness in the Duroc breed. Usually, leg scores are used as the threshold values for independent culling on the basis of leg weakness. Since there seems to be an intermediate or high genetic correlation between some of the performance traits and leg score traits as suggested in our study, multiple trait selection for both performance and leg score traits could be a more effective method for selection than independent culling on the basis of leg weakness. Our study also suggested that inclusion of contemporary groups, other fixed cffects, and a covariate in the model for estimation of breeding value is necessary even in a situation where environmental effects are strictly controlled. This showed that utilization of BLUP or REML methodology for deciding the statistical model for estimation of breeding value has an advantage over utilization of selection indices.

\section{References}

1) Akaike H. A newlook at the statistical model identification. IEEE Transaction on Automatic Control AC-19: 716-723. 1974.

2) Cameron ND, Curran MK. Selection for components of efficient lean growth rate in pigs 4. Genetic and phenotypic parameter estimates and correlated response in performance test traits with ad-libitum feeding. Animal Production, 59 : 281-292. 1994. 
3) Goedegebuure SA, Rothschild MF, Christian LL, Ross RF. Severity of osteochondrosis in three genetic lines of Duroc swine divergently selected for front-leg weakness. Livestock Production Science, 19 : 487-498. 1988.

4) Groeneveld E, Kovac M, Wang T, Fernando RL. A generalized computing procedure for setting up and general purpose BLUP package for multivariate prediction and estimation. Archiv fur Tierzucht, 35 : 399-412. 1992.

5) Groeneveld E. REML VCE Version 3.2 User's Guide. 1996.

6) Grøndalen T. Osteochondrosis and arthrosis in pigs. I. Incidence in animals up to $120 \mathrm{~kg}$ live weight. $A c t a$ Veterinariae Scandinavica, 15 : 1-25. 1974.

7) Henderson, CR. Sire evaluation and genetic trends. Proceedings of the Animal Breeding and Genetics Symposium in Honor of Dr. J. L. Lush, : 10-41. 1973.

8) Hyodo I. Experiment on building a strain of the Landrace breed. Interim report. Tokyo Metropolitan Livestock Experiment Station, 8. 1983.

9) Jorgensen B. Effect of different energy and protein levels on leg weakness and osteochondrosis in pigs. Livestock Production Science, 41 : 171-179. 1995.

10) Kadowaki H, Suzuki K, Ogawa Y, Itoh M. Relationship of leg soundness trait to meat performance and body size in Duroc swine. Japanese Journal of Swine Science, 35 : 107-113. 1998.

11) Kurita $T$, Kitajima $H$, Ieiri $S$. The improvement of litter size and its genetic trend using animal model BLUP in pigs. Japanese Journal of Swine Science, 36 : 111-116. 1999.

12) Lakhani GP, Bhadauria SS. Heritability and variability in the birth weight of indigenous pigs. Indian Journal of Animal Research, 22 : 49-50. 1988.

13) Li XW, Kennedy BW. Genetic parameters for growth rate and back fat in Canadian Yorkshire, Landrace, Duroc and Hampshire pigs. Joumal of Animal Science, 72 : 1450-1454. 1994.

14) Long $T$, Brandt $H$, Hammond $K$. Application of best linear unbiased prediction to genetic evaluation in pigs. Pig News and Information, 12 : 217-219. 1991.
15) Lundeheim N. Genetic analysis of osteochondrosis and leg weakness in the Swedish pig progeny testing scheme. Acta Agriculturae Scandinavica, $37: 159$ 173. 1987.

16) Patterson HD, Thompson R. Recovery of inter-block information when block sizes are unequal. Biometrika, 58 : 545-554. 1971.

17) SAS Institute Incorporated. SAS Technical Report P-229, SAS/STAT Software: Changes and Enhancements, Release 6.07, Cray, NC : SAS Institute Incorporated, 287-366. 1992.

18) Satoh M. Best linear unbiased prediction of breeding value for multiple traits by animal model. Bulletin of the Computing Center for Research in Agriculture, Forestry and Fishery, A $26: 61-127.1990$.

19) Satoh M, Nishida A, Furukawa T. The influence of variation in the generation effect on the accuracy of predicting breeding values. A computer simulation on a closed herd of swine. Animal Science and Technology, $63:$ 457-461. 1992.

20) Van Steenbergen EJ, Kanis E, Van Der Steen HAM. Genetic parameters of fattening performance and exterior traits of boars tested in central stations. Livestock Production Science, 24 : 65-82. 1990.

21) Villanueva B, Wray NR, Thompson R. Prediction of asymptotic rates of response from selection on multiple traits using univariate and multivariate best linear unbiased predictors. Animal Production, $57: 1-13$. 1993.

22) Wada $Y$, Kashiwagi $N$. Selecting statistical models with information statistics. Journal of Dairy Science, $73:$ 3575-3582. 1990.

23) Weller JI, Misztal I, Gianola D. Genetic analysis of distocia and calf mortality in Israel-Holstein by threshold and linear models. Journal of Dairy Science, 71 : 2491-2501. 1988.

24) Weller JI, Ron M. Genetic analysis of fertility traits in Israel-Holstein by linear and threshold models. Journal of Dairy Science, 75 : 2541-2548. 1992.

25) Wray NR, Hill WG. Asymtotic rates of response from index selection. Animal Production, $49: 217-$ 227. 1989. 